ANNO ELFGEN

Die Mejora 


\section{NEUE KÖLNER \\ RECHTSWISSENSCHAFTLICHE \\ ABHANDLUNGEN}

HERAUSGEGEBEN VON

DER RECHTSWISSENSCHAFTLICHEN FAKULTÄT

DER UNIVERSITÄT ZU KÖLN

H E FT 21

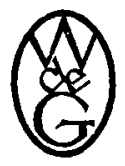

Berlin 1962

WALTER DE GRUYTER \& CO.

vormals G. J. Göschen'sche Verlagshandlung · J. Guttentag, Verlagsbuchhandlung Georg Reimer - Karl J. Trübner - Veit \& Comp. 


\title{
DIE MEJORA
}

\section{Geschichte und Dogmatik im spanischen und südamerikanischen Recht}

\author{
Von \\ Dr. Anno Elfgen
}

Köln

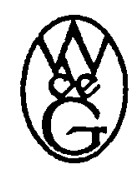

Berlin 1962

WALTER DE GRUYTER \& CO.

vormals G. J. Göschen'sche Verlagehandlung · J. Guttentag, Verlagsbuchhandlung Georg Reimer . Karl J. Trübner . Veit \& Comp. 
Archiv.Nr. $270862 / 4$

Satz und Druck: Berliner Buchdruckerei Union GmbH., Berlin SW 61 Alle Recbte, cinschlieblich des Rechtes der Hexstellung von Fotokodien und Mikrofilmen, vorbehalten 